OPEN ACCESS

Edited by:

Aristides (Aris) Moustakas, Queen Mary University of London, United Kingdom

Reviewed by:

Tim Adriaens,

Research Institute for Nature and

Forest, Belgium

Panayiotis Dimitrakopoulos, University of the Aegean, Greece

*Correspondence: Ivan Deriu ivan.deriu@ext.jrc.ec.europa.eu

Specialty section: This article was submitted to Environmental Informatics, a section of the journal Frontiers in ICT

Received: 30 March 2017 Accepted: 05 July 2017

Published: 27 July 2017

Citation:

Deriu I, D'Amico F, Tsiamis K, Gervasini E and Cardoso AC (2017) Handling Big Data of Alien Species in Europe: The European Alien Species Information Network Geodatabase.

Front. ICT 4:20.

doi: 10.3389/fict.2017.00020

\section{Handling Big Data of Alien Species in Europe: The European Alien Species Information Network Geodatabase}

\author{
Ivan Deriu*, Fabio D’Amico, Konstantinos Tsiamis, Eugenio Gervasini and \\ Ana Cristina Cardoso
}

European Commission, Joint Research Centre - Directorate for Sustainable Resources, Water \& Marine Resources Unit, Ispra, Italy

Building and managing large datasets of alien species is crucial to research, management, and control of biological invasions. To this end, the European Alien Species Information Network (EASIN) platform aggregates, integrates, and harmonizes spatio-temporal data regarding alien species in Europe, including both invasive and non-invasive alien species. These data are stored in the EASIN Geodatabase after their harvesting from relevant sources in the frame of a global and European databases partnership and scientific literature. The ownership of the data remains with its source, which is properly cited and linked. The process of data harvesting is performed through the EASIN Data Broker system, which retrieves the information related to alien species data in Europe and stores them in a normalized database structure. Data are subsequently refined through validation, cleansing, and standardization processes and finally stored in the EASIN Geodatabase. All data are finally visualized and shown in occurrence maps at different levels of spatial visualization. Analysis of the data contained in the EASIN Geodatabase through flexible web services offered by the system has already provided useful input in scientific works and policies on biological invasions. Data from European Union (EU) member state official surveillance systems, within the framework of the EU Regulation $1143 / 2014$ on invasive alien species, are expected to contribute to the update of the EASIN Geodatabase. In addition, data from citizen science initiatives will further enrich the Geodatabase after appropriate validation. In this article, we describe and discuss the technical aspects, data flow and capabilities of the EASIN Geodatabase.

Keywords: alien, dataset, European Alien Species Information Network, Europe, Geodatabase, network

\section{INTRODUCTION}

There are more than 14,000 alien species that have been reported so far in Europe (Katsanevakis et al., 2015). About $10 \%$ of them correspond to invasive alien species (IAS) based on the Tens Rule (Williamson and Fitter, 1996). IAS threaten or adversely impact upon biodiversity and related ecosystem services of Europe [Millennium Ecosystem Assessment (MEA), 2005; Ricciardi et al., 2013; EU, 2014; Jeschke et al., 2014]. As a conservative estimate, IAS cost the European Union (EU) Member States $€ 12$ billion in damages on annual basis (Kettunen et al., 2009) but cumulated costs probably reach $€ 20$ billion per year (IEEP, 2016). In addition, there is an increasing trend toward introduction of new alien species (Essl et al., 2015; Roques et al., 2016; Seebens et al., 2017). Recognizing the need 
for a coordinated set of actions to prevent, control, and mitigate the adverse impact of IAS on biodiversity and related ecosystem services, the European Parliament and the Council have adopted the EU Regulation no. 1143/2014 (EU, 2014; hereafter referred to as the IAS Regulation) on the prevention and management of the introduction and spread of IAS, which entered into force on January 1, 2015.

Managing large datasets of alien species is crucial to research, management, and control of biological invasions. Handling such large datasets poses a great challenge, since the information available is generally scattered across many different information systems and databases (Panov and Gollasch, 2004; Gatto et al., 2013). In addition, data format and information about the data (metadata) are frequent limitations to the interoperability of data repositories and information systems (Katsanevakis et al., 2012).

The European Alien Species Information Network (EASIN ${ }^{1}$ ) aims to provide a single repository of alien species data for accessing all the information necessary to underpin alien-species-related policy and evidence-based decision-making (Katsanevakis et al., 2013a). A key component of the EASIN system is the EASIN Catalog: a comprehensive list of alien species in Europe, currently including information on more than 14,000 taxa in a wide range of environments. Both invasive and non-invasive alien species are included. IAS are tagged as "high-impact" species in EASIN and are considered those that are highlighted by the lists of Delivering Alien Invasive Species Inventories for Europe, Global Invasive Species Database, NOBANIS (European Network on IAS), CABI's Invasive Species Compendium, MedPAN (Network of Marine Protected Areas managers in the Mediterranean), and SEBI-2010 (list of worst IAS threatening biodiversity in Europe; Streamlining European 2010 Biodiversity Indicators), to cause severe ecological and socio-economic impacts in Europe and/ or globally. Other species are tagged as "low/unknown impact" species (see also Katsanevakis et al., 2012). In the latest version of EASIN (v.4.1), there are 908 species tagged as "high-impact," while 13,102 species are tagged as "low/unknown impact."

For each alien species of the EASIN Catalog information is available on the year and country of the first record in Europe, alien status (alien, cryptogenic, questionable), native range, taxonomy, synonyms, common names, environment, pathways, vectors, and impact. Links to factsheets are also provided for selected taxa (Katsanevakis et al., 2015). Given the vast amount of information recorded in EASIN and the need for constant updating and revision, an Editorial Board has been established to ensure the quality and updates of the information contained in the EASIN Catalog (Tsiamis et al., 2016).

Besides the EASIN Catalog, EASIN provides aggregated and integrated spatial data on alien species in Europe as well as online mapping tools for the retrieval of these data, through the EASIN Geodatabase. All spatial data are visualized and shown in occurrences maps at different levels (country, grid $10 \mathrm{~km} \times 10 \mathrm{~km}$, river basin, marine ecoregion). In the current paper, we demonstrate the approach, functionality, and technical background of the EASIN Geodatabase, which is the backbone of the EASIN

${ }^{1} \mathrm{http} / / /$ easin.jrc.ec.europa.eu. network, responsible for the collection, quality control, harmonization, integration, storage, visualization, and dissemination of large datasets on alien species in Europe, coming from various sources.

\section{DESCRIPTION OF THE EASIN GEODATABASE}

\section{Data Sources}

The EASIN Geodatabase hosts about 50 millions of alien species spatial data (i.e., records) across Europe, all originating from a network of data sources, named as EASIN Data Partners (Table 1). These are global, regional, and national databases or repositories that have agreed to provide EASIN with spatial information of alien species in Europe. These sources do not always contain alien species data exclusively, but they might host broader species biodiversity information, including also native species in Europe, such as in the case of Global Biodiversity Information Facility. However, EASIN performs a targeted harvesting only to species which are considered alien or partly alien in the whole European scale (see Data Harvesting). Ownership of the data remains with its source, which is properly cited and linked in the EASIN Geodatabase. The EASIN Data Partners gain increased visibility and networking possibilities through EASIN, and can also benefit from mutual data exchange. Additional and updated spatial data are being gathered through EASIN-Lit (Trombetti et al., 2013), which contributes to enriching the Geodatabase with geo-referenced data published in the scientific literature. By

TABLE 1 | European Alien Species Information Network (EASIN) Data Partners and details on their technology, access, and update schedule in the EASIN Geodatabase.

\begin{tabular}{|c|c|c|c|}
\hline Data partner & Technology & Access & $\begin{array}{l}\text { Update } \\
\text { schedule }\end{array}$ \\
\hline Global Biodiversity Information Facility & Web service & Online & Monthly \\
\hline $\begin{array}{l}\text { Global Invasive Species Information } \\
\text { Network }\end{array}$ & $\begin{array}{l}\text { MS access } \\
\text { DB }\end{array}$ & Offline & $\begin{array}{l}\text { No } \\
\text { schedule }\end{array}$ \\
\hline $\begin{array}{l}\text { Regional Euro-Asian Biological Invasions } \\
\text { Center }\end{array}$ & MS SQL DB & $\begin{array}{l}\text { Online } \\
\text { restricted }\end{array}$ & Monthly \\
\hline $\begin{array}{l}\text { Hellenic Network on Aquatic Invasive } \\
\text { Species (ELNAIS) }\end{array}$ & ArcGIS DB & Offline & $\begin{array}{l}\text { No } \\
\text { schedule }\end{array}$ \\
\hline $\begin{array}{l}\text { International Commission for Scientific } \\
\text { Exploration of the Mediterranean Sea } \\
\text { (CIESM) }\end{array}$ & ArcGIS DB & Offline & $\begin{array}{l}\text { No } \\
\text { schedule }\end{array}$ \\
\hline EASIN-LIT & $\begin{array}{l}\text { Excel file/ } \\
\text { ArcGIS DB }\end{array}$ & Offline & Monthly \\
\hline HCMR-European Environmental Agency & Excel file & Offline & $\begin{array}{l}\text { No } \\
\text { schedule }\end{array}$ \\
\hline $\begin{array}{l}\text { International Union for Conservation of } \\
\text { Nature online information system for } \\
\text { monitoring invasive non-native species in } \\
\text { marine protected areas (MEDMIS) }\end{array}$ & $\begin{array}{l}\text { PostgreSQL } \\
\text { DB }\end{array}$ & $\begin{array}{l}\text { Online } \\
\text { restricted }\end{array}$ & Monthly \\
\hline $\begin{array}{l}\text { Marine Mediterranean Invasive Alien } \\
\text { Species }\end{array}$ & Excel file & Offline & $\begin{array}{l}\text { No } \\
\text { schedule }\end{array}$ \\
\hline Norwegian Biodiversity Information Center & Excel file & Offline & $\begin{array}{l}\text { No } \\
\text { schedule }\end{array}$ \\
\hline
\end{tabular}


March 2017, 11 data sources have been included as EASIN Data Partners.

\section{Data Harvesting}

The targeted information for the EASIN Geodatabase is the alien species spatial data in Europe, regardless if they are invasive or not. These can also include partly native species in Europe, i.e., species which are alien in some areas of Europe but native to some others. The process of harvesting information is done through the EASIN Data Broker system (Figure 1). This system is able to retrieve heterogeneous species data from different categories of data sources and formats and store them in a normalized database structure. In more detail, it screens and harvests information from the EASIN Data Partners based on the scientific names of the alien species listed in the EASIN Catalog. The EASIN Data Broker system identifies only the binomial of each species, without taking into consideration the species scientific authorities. As a result, typos and/or various formats of the species authorities in other sources do not affect the harvesting of the targeted information. In addition, scientific synonyms of each species are considered during harvesting. This is achieved through the information contained in the EASIN Catalog. For each species in the Catalog all scientific synonyms are also included, based on the Integrated Taxonomic Information System for terrestrial and freshwater species, and the World Register of Marine Species (WoRMS) for marine species. Thus, the EASIN Data Broker system can spot and harvest information based not only on the species binomial but also on its scientific synonyms.

Once the EASIN Data Broker system spots the binomial of a species within a dataset of an EASIN Data Partner, it will harvest targeted information about the specific species: (a) its location (name of the area and/or coordinates), (b) its date of collection (year), and (c) a reference to the original source of the record. Inside the EASIN system each Data Partner has a specific database and unique identifier. For each new data harvesting of a Data Partner a new dataset with related metadata is created.

\section{Data Processing}

Once harvested, the data are processed through different transformation steps: validation, cleansing, standardization, and geocoding (Figure 1). The validation and cleansing processes verify if the harvested data contain all the required information

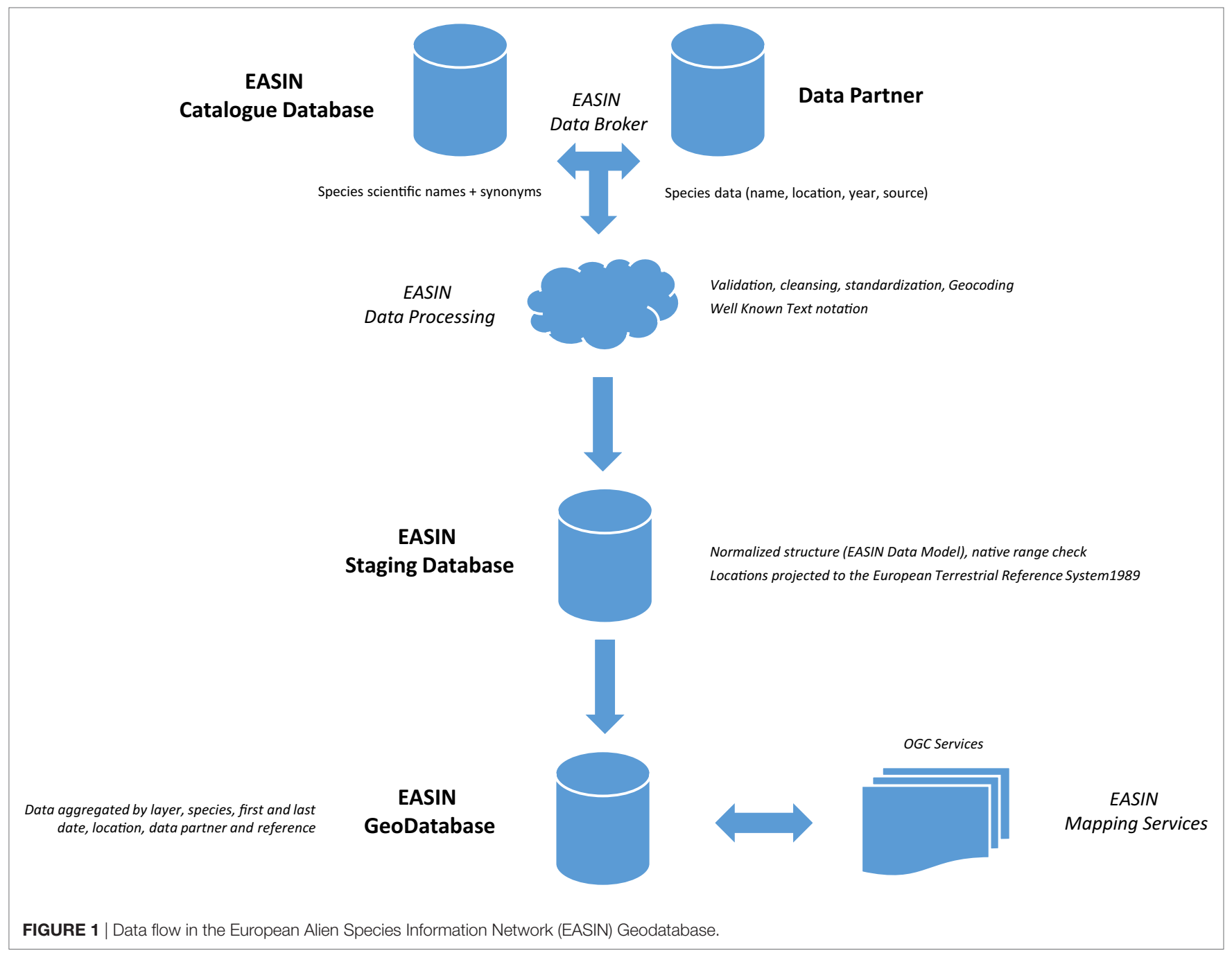


(species name, date, location, reference), and if the reported location falls in one of the countries included in the EASIN geographical coverage of Europe. ${ }^{2}$ In case the harvested data contains spatial information through coordinates, a further verification checks if the reported location corresponds with the relevant environment of the species. This is achieved through the information contained in the EASIN Catalog for the environment of each species (terrestrial, freshwater, marine, oligohaline-see also Katsanevakis et al., 2015). As a result, the verification check can spot a mismatch of a species environment compared with a geo-reference occurrence. Thus, a record containing a terrestrial or freshwater species reported in the sea will be discarded. Similarly, a marine species reported in a terrestrial or freshwater location will be also excluded. After validation and cleansing, the information is standardized following the EASIN Data model. This model organizes and normalizes the information coming from the Data Partners. During this process unique identifiers for locations and references are created.

The format of the aggregated spatial information regarding the locations is varying across the EASIN Data Partners. To this end, a conversion of this information is performed through the Well Known Text $\left(\mathrm{WKT}^{3}\right)$ markup language, ensuring interoperability of the spatial information aggregated. Spatial information retrieved from the Data Partners is stored in the coordinate system of World Geodetic System 1984 (WGS84). ${ }^{4}$ In case the original information contains the location of a record in a different coordinate system, a re-projection process is performed through Arc GIS. When no coordinates are available, a conversion of cited place names or maps to a spatial format is performed with the best possible accuracy through the Google Geocoding. ${ }^{5}$

\section{Staging Database}

After the data have been processed, the information is moved to a normalized intermediate database, named EASIN Staging database (Figure 1). This structure allows transformation of the information in data formats that can be used for specific purposes, e.g., for serving the EASIN mapping (see Geodatabase and Mapping Services). In addition, through the Staging database the information can be transformed to the schemas required by the INSPIRE Regulation (INSPIRE Framework Directive 2007/2/EC; EU, 2007; INSPIRE, 2013). The EASIN Staging database contains the information about the location and the references in separate data collections in order to reduce data redundancy (e.g., one location may be reported in several different records) and improve data integrity (Figure 2). In this phase, the dates of the records are approximated to years, while locations are processed to contain the spatial information also in the European Terrestrial Reference System 1989 (ETRS89) $^{6}$ for coordinates. In the EASIN Staging database, the locations are intersected with the EASIN layers, in order to show in which country, grid cell $10 \mathrm{~km} \times 10 \mathrm{~km}$, marine ecoregion or river basin they fall. This process is fundamental for

${ }^{2}$ https://easin.jrc.ec.europa.eu/Catalogue.

${ }^{3}$ https://en.wikipedia.org/wiki/Well-known_text.

${ }^{4}$ https://en.wikipedia.org/wiki/World_Geodetic_System.

${ }^{5} \mathrm{https} / /$ developers.google.com/maps/documentation/geocoding/intro.

${ }^{6}$ https://en.wikipedia.org/wiki/European_Terrestrial_Reference_System_1989. creating data aggregations by layers. The data are also processed against the information contained in the EASIN Catalog regarding the native range of a partly native species in Europe. This information is available in the EASIN Catalog in country-level. Once a partly native species is harvested from a Data Partner, the Staging database marks which occurrences fall inside countries which have been tagged as "native range" for the certain species in Europe. For example, if a partly native species in Europe is considered native in Italy, based on the information contained in the EASIN Catalog, then all harvested occurrences of the species falling in Italy will be set as native. The native range of the partly native species in Europe can be updated by the EASIN Editorial Board.

\section{Geodatabase and Mapping Services}

The EASIN Geodatabase is populated by extracting the data from the Staging database, aggregated by layer, species, first and last date, location, data partner, and reference (Figure 1). The result is a data format suitable for providing all the necessary information needed by the EASIN mapping services, which visualizes alien species occurrences' maps. The maps can be created at four levels, as many as the EASIN layers: by country, grid $10 \mathrm{~km} \times 10 \mathrm{~km}$ (based on EEA, 2012 reference grid), river basins, and marine ecoregions. When it comes to partly native species in Europe, their occurrences falling in countries which have been tagged as "native range" are depicted in a different color compared with the occurrences falling in countries tagged as "alien range." All the maps are exposed through Open Geospatial Consortium $\left(\mathrm{OGC}^{7}\right)$ compliant services as Catalog Service for the Web, Web Map Service, and Web Feature Service.

Aiming at more tailored distribution maps of alien species in Europe, the EASIN Geodatabase can filter the related information based on the selection of the environment (terrestrial, freshwater, marine, oligohaline), species status (alien, cryptogenic, questionable), specific taxonomic groups (in various taxonomic levels from species to Kingdom), and pathways of introduction based on the scheme proposed by Hulme et al. (2008). Regarding the latter EASIN will gradually align its pathways categorization to the one proposed by the Convention of Biological Diversity (CBD, 2014) aiming at achieving synchronization and harmonizing of information on alien species pathways (Tsiamis et al., 2017a). Moreover, a distinction between high-impact and low-impact alien species is possible when depicting the occurrences maps.

\section{IMPACT OF THE EASIN GEODATABASE}

The EASIN Geodatabase has been used to support scientific research on biological invasions, addressing (a) distribution patterns (Katsanevakis et al., 2013b,c), (b) pathways and gateways of introduction (Katsanevakis et al., 2013c, 2014; Nunes et al., 2014, 2015; Essl et al., 2015; Roques, 2015; Pergl et al., 2017; Tsiamis et al., 2017a), (c) risk and impact assessments of invasive species (Katsanevakis et al., 2014, 2016; Perdikaris et al., 2016), and (d) Horizon Scanning exercises (Roy et al., 2015).

${ }^{7}$ http://www.opengeospatial.org/. 


\section{EASIN Staging Database (v3.0)}

\section{Schema of the Normalized Records}

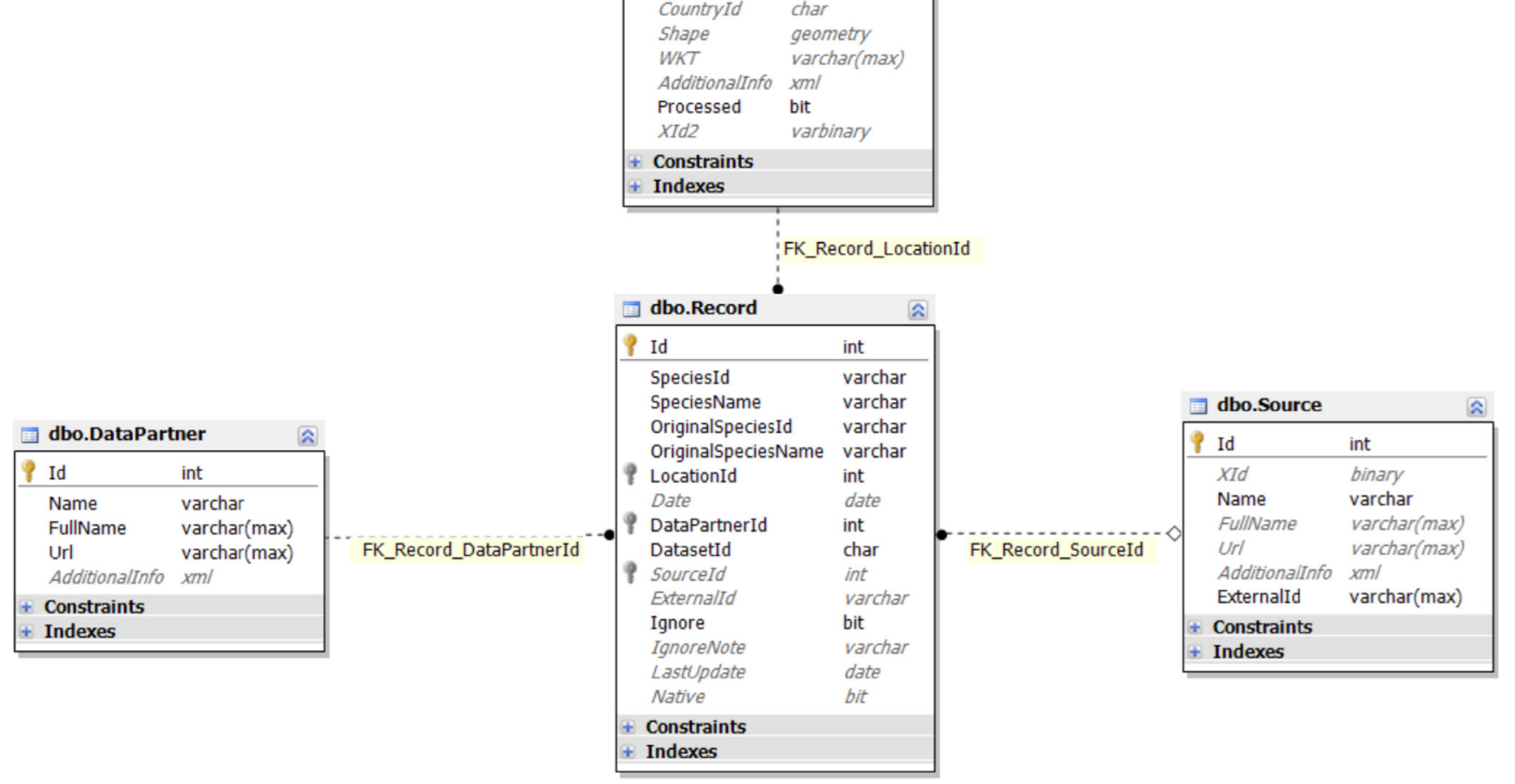

FIGURE 2 | Schema of the normalized records in the European Alien Species Information Network (EASIN) Staging Database, containing the information about the location and the references in separate data collections.

European Alien Species Information Network constitutes the core information system supporting MS in the implementation of the IAS Regulation (EU, 2014, Art. 25). The 37 IAS of Union concern, published in the Commission Implementing Reg. $1141 / 2016$ in application of the IAS Regulation, are all included in EASIN and tagged distinctively as "Union concern." The information stored in the EASIN Geodatabase regarding these 37 taxa has been used as the basis for the establishment of a distribution baseline of those species in terms of the IAS Regulation. This baseline is an important tool supporting the implementation of the IAS Regulation, the Art. 16 in particular regarding early detections of the IAS of Union concern, and also provides a factual basis for the review of the application of the IAS Regulation (Tsiamis et al., 2017b). In addition, information found in the EASIN Geodatabase has been used for the review of the EU Biodiversity Strategy, especially when it comes to spatial patterns of the main pathways of introduction of alien species into Europe, including both invasive and non-invasive species (EU, 2015).

\section{CHALLENGES AND SOLUTIONS}

Handling heterogeneous information coming from different sources and providing maps to the users requires to address two main challenges: (a) harmonizing of the information coming from different data sources and (b) minimizing the time required for showing a map to the user.
Normalizing the data (references and locations) and using a unique format for storing the information has been crucial for further managing the data and producing integrated maps and reports. In particular, aside the effort on implementing the data processes, the solution has been the choice to use only one projection (WGS84) for uniquely identifying the locations. Each EASIN Data Partner has its own particular data model, storage type, publishing approach, and standards that require a specific EASIN data brokering procedure (Table 1).

The EASIN Geodatabase output is to provide to the users occurrences maps of alien species in Europe. Taking into account the vast information included in the Geodatabase and the processing of it, there has been a challenge to visualize maps in the EASIN interface through the shortest possible time. In order to improve the reading performance, the first solution implemented has been the de-normalizing and grouping of some information. After the massive update of EASIN Geodatabase during 2016, which reached the amount of almost 50 million of data processed, it has been clear that the de-normalization solution was not enough anymore, considering also the large amount of space occupied by the redundant information. The solution has been found in the creation of a "dynamic query pre-cooking." Every time a user sends a query to the Geodatabase, the result of the query is stored in a specific location. Thus, a unique identifier is built for each query result through a hash algorithm. If a user sends a query already present in the EASIN Geodatabase the 
system retrieves the final result without further processing. Any new release of the Geodatabase results in deleting the current pre-cooked queries, as the aggregations in the new release may differ from the previous one.

Maps provided by the EASIN Geodatabase are exclusively based on the information provided by the EASIN Data Partners. However, this information might be biased due to varying monitoring efforts, geographical coverage, environment, and taxonomic groups addressed in each original dataset of an EASIN Data Partner. As a principle, EASIN targets to be enlarged with as many Data Partners as possible hosting information on alien species in Europe. Then, it is up to the user to select only the Data Partners which are considered more appropriate for an optimal visualization of occurrences of alien species in Europe and correct the data from potential biases.

\section{FUTURE DEVELOPMENTS}

Up to March 2017 there have been 11 EASIN Data Partners, but at least 7 new ones will be integrated in EASIN by the end of 2017: Icelandic Institute of Natural History, Academy of Science of Moldova, National Biodiversity Data Center-Ireland, Great Britain Non-Native Species Secretariat, Croatian Agency for the Environment and Nature, Azorean Biodiversity Portal, Life Project STOPVESPA.

The EASIN Geodatabase will be further enriched by records of IAS of Union concern [EU, 2014, Art. 3(3) and 4(1)] submitted by the EU Member States' Competent Authorities for the IAS Regulation in an Early Warning and Rapid Eradication Notification System (NOTSYS), developed with close links to EASIN. Through this system, the European Commission and all Member States are notified about new occurrences of IAS of Union concern detected on EU territory. NOTSYS is also used for reporting eradication measures as well as their effectiveness, as foreseen in Art. 16-17 of the IAS Regulation.

In addition, it is under consideration that data of alien species coming from citizen science initiatives in Europe (e.g., the JRC smartphone application "Invasive Aliens Species in Europe"-Tsiamis et al., 2017c), which are increasingly recognized as an important source of alien species data (Thiel et al., 2014; Adriaens et al., 2015; Daume, 2016), will further enrich the EASIN Geodatabase after appropriate validation. In this context, the EASIN Geodatabase could offer an aggregation and harmonization point for data coming from all citizen science projects related with alien species in Europe.

Prioritization of areas which are most sensitive and/or susceptible to biological invasions is critical for their effective management (McGeoch et al., 2015). To this end, the EASIN Geodatabase will include an additional layer within its mapping services on the Natura 2000 conservation network, in the frame of the Birds Directive (EU, 2009) and the Habitats Directive (EU, 1992). Moreover, the inclusion of the Marine Strategy Framework Directive (EU, 2008) marine regions as a distinct layer in EASIN maps is also under consideration. This would facilitate suitable filtering of the related information regarding marine alien species in terms of the Directive's purposes. In addition, the linkage with the IAS Regulation will not be limited exclusively to the 37 IAS of
Union concern, but to a wider context of the EASIN Geodatabase species, taking into account the possible inclusion of additional species in the Union concern list, and the establishment of species of "Regional," "Member State" concern, and IAS of EU "outermost regions" (Art. 11, 12, and 6, respectively, of the IAS Regulation).

Speeding up the data processing is a critical aspect for any procedure that integrates data from different sources and requires constant update. In particular, when spatial information is shown on aggregated maps, as in the case of EASIN, a less timedemanding data process is required. In order to retrieve huge amounts of data, such as in the case of the grid $10 \mathrm{~km} \times 10 \mathrm{~km}$, the usual approach of processing the information record by record cannot be the most efficient approach. A location is usually shared among different records, thus the number of locations is less than the number of records. Therefore, locations can be processed faster than records. To this end, the locations must be normalized, as in the EASIN Staging database, before being processed. By adopting this approach in EASIN, the time required for processing millions of records can be reduced from weeks to hours.

\section{CONCLUSION}

Tackling biological invasions effectively relies on the availability of up-to-date scientific information, and requires the sharing of knowledge on the topic in order to enhance science-based decision-making (Panov et al., 2011; Katsanevakis et al., 2012; McGeoch et al., 2012; Roy et al., 2014; Groom et al., 2017a). In addition, it is crucial to have a single aggregation point, where available knowledge on alien species from various data sources is integrated, harmonized, and standardized (Panov and Gollasch, 2004; Katsanevakis et al., 2013a; Ojaveer et al., 2014). This knowledge should be openly displayed in ways that is findable, accessible and interoperable, encouraging exchange, and dissemination of data with other existing data platforms (Groom et al., 2015, 2017b; Lucy et al., 2016), in line with the EU Open Science Strategic Priority, and the plan of the Commission to develop the European Open Science Cloud (EU, 2016).

European Alien Species Information Network is the core of the information support system supporting the implementation of the IAS Regulation, while at the same time there has been a linkage with the EU Biodiversity policy. Connection with other policies on alien species, such as the MSFD and Natura 2000 sites is also under consideration. Therefore, it is crucial that the information provided by the EASIN Geodatabase is of high quality, updated, accessible, and easily processed by all interested stakeholders.

European Alien Species Information Network, through the EASIN Geodatabase, offers both a single aggregation point of alien species spatial data and flexible services for mapping alien species occurrences within Europe. EASIN works in partnership with European and global data providers to facilitate access to key data and information on alien species, promotes the principles of open-source, ensures accreditation of data publishers and data owners, highlights the work of other initiatives, increases their visibility, and facilitates direct access to the original information/data.

The number of alien species data processed by the EASIN Geodatabase will considerably increase in the near future due to 
the incorporation of new EASIN Data Partners, NOTSYS data, and citizen science data. This additional amount of information will test the efficiency and endurance of the EASIN Geodatabase, and possibly new adaptations and technical solutions might be needed. In addition, the continuous growth of the EASIN Geodatabase will test the soundness of the statistical correlations performed based on EASIN data, such as in the case of the analyses on pathways of introduction or distribution patterns of alien species. This is because bigger data sets could result in higher bias and bring up spurious correlations (Silver, 2012; Donoho and Jin, 2015) with possible implications to outcomes crucial to biological invasions research and to related policies. To this end, careful selection of data and appropriate statistical design should

\section{REFERENCES}

Adriaens, T., Sutton-Croft, M., Owen, K., Brosens, D., van Valkenburg, J., Kilbey, D., et al. (2015). Trying to engage the crowd in recording invasive alien species in Europe: experiences from two smartphone applications in northwest Europe. Manag. Biol. Invasion 6, 215-225. doi:10.3391/mbi.2015.6.2.12

CBD. (2014). Pathways of Introduction of Invasive Species, Their Prioritization and Management, UNEP/CBD/SBSTTA/18/9/Add.1.Vol. 6. Montreal, Canada: UNEP/CBD/SBSTTA. 1-18.

Daume, S. (2016). Mining Twitter to monitor invasive alien species-an analytical framework and sample information topologies. Ecol. Inform. 31, 70-82. doi:10.1016/j.ecoinf.2015.11.014

Donoho, D., and Jin, J. (2015). Higher criticism for large-scale inference, especially for rare and weak effects. Stat. Sci. 30, 1-25. doi:10.1214/14-STS506

EEA. (2012). European Environmental Agency Reference Grid. Available at: http:// www.eea.europa.eu/data-and-maps/data/eea-reference-grids-1

Essl, F., Bacher, S., Blackburn, T., Booy, O., Brundu, G., Brunel, S., et al. (2015). Crossing frontiers in tackling pathways of biological invasions. Bioscience 65, 769-782. doi:10.1093/biosci/biv082

EU. (1992). Council directive 92/43/EEC of 21 May 1992 on the conservation of natural habitats and of wild fauna and flora. Off. J. Eur. Union L206, 7-50.

EU. (2007). Directive 2007/2/EC of the European parliament and of the council of 14 March 2007 establishing an infrastructure for spatial information in the European community (INSPIRE). Off. J. Eur. Union L108, 1-14.

EU. (2008). Directive 2008/56/EC of the European parliament and of the council of 17 June 2008 establishing a framework for community action in the field of marine environmental policy (marine strategy framework directive). Off. J. Eur. Union L164, 19-40.

EU. (2009). Directive 2009/147/EC of the European parliament and of the council of 30 November 2009 on the conservation of wild birds. Off. J. Eur. Union L184, $7-25$.

EU. (2014). Regulation (EU) No 1143/2014 of the European parliament and of the council on the prevention and management of the introduction and spread of invasive alien species. Off. J. Eur. Union L315, 35-55.

EU. (2015). Commission staff working document. EU assessment of progress in implementing the EU biodiversity strategy to 2020. Accompanying the document report from the commission to the European parliament and the council the mid-term review of the EU biodiversity strategy to 2020. SWD $187,77$.

EU. (2016). Communication from the Commission to the European Parliament, the Council, the European Economic and Social Committee and the Committee of the Regions. European Cloud Initiative - Building a Competitive Data and Knowledge Economy in Europe. COM/2016/0178 final. 13, Brussels: European Commission.

Gatto, F., Katsanevakis, S., Vandekerkhove, J., Zenetos, A., and Cardoso, A. C. (2013). Evaluation of online information sources on alien species in Europe the need of harmonization and integration. Environ. Manage. 51, 1137-1146. doi:10.1007/s00267-013-0042-8

Groom, Q., Desmet, P., Vanderhoeven, S., and Adriaens, T. (2015). The importance of open data for invasive alien species research, policy and management. Manag. Biol. Invasion 6, 119-125. doi:10.3391/mbi.2015.6.2.02 be ensured in order to limit correlated errors when handling big data sets (see also Moustakas, 2017 and references therein).

\section{AUTHOR CONTRIBUTIONS}

All authors have contributed to the present manuscript. ID and FD focused in the design of the EASIN Geodatabase, AC in the concept of the work, and KT and EG in drafting the manuscript.

\section{ACKNOWLEDGMENTS}

The authors wish to thank the European Commission's DirectorateGeneral for Environment (DG ENV) for their support.

Groom, Q., Weatherdon, L., and Geijzendorffer, I. R. (2017a). Is citizen science an open science in the case of biodiversity observations? J. Appl. Ecol. 54, 612-617. doi:10.1111/1365-2664.12767

Groom, Q., Adriaens, T., Desmet, P., Simpson, A., De Wever, A., Bazos, I., et al. (2017b). Seven recommendations to make your invasive alien species data more useful. Front. Appl. Math. Stat. 3:13. doi:10.3389/fams.2017.00013

Hulme, P. E., Bacher, S., Kenis, M., Klotz, S., Kühn, I., Minchin, D., et al. (2008). Grasping at the routes of biological invasions: a framework for integrating pathways into policy. J. Appl. Ecol. 45, 403-414. doi:10.1111/j.1365-2664. 2007.01442.x

IEEP. (2016). Institute for European Environmental Policy. Available at: http://www. ieep.eu/work-areas/biodiversity/invasive-alien-species

INSPIRE. (2013). D2.8.III.19 INSPIRE Data Specification on Species Distribution Technical Guidelines. INSPIRE Thematic Working Group Species Distribution.

Jeschke, J. M., Bacher, S., Blackburn, T. M., Dick, J. T. A., Essl, F., Evans, T., et al. (2014). Defining the impact of non-native species. Conserv. Biol. 28, 1188-1194. doi:10.1111/cobi.12299

Katsanevakis, S., Bogucarskis, K., Gatto, F., Vandekerkhove, J., Deriu, I., and Cardoso, A. C. (2012). Building the European alien species information network (EASIN): a novel approach for the exploration of distributed alien species data. BioInvasions Rec. 1, 235-245. doi:10.3391/bir.2012.1.4.01

Katsanevakis, S., Deriu, I., D’Amico, F., Nunes, A. L., Sanchez, S. P., Crocetta, F., et al. (2015). European alien species information network (EASIN): supporting European policies and scientific research. Manag. Biol. Invasion 6, 147-157. doi:10.3391/mbi.2015.6.2.05

Katsanevakis, S., Genovesi, P., Gaiji, S., Nyegaard Hvid, H., Roy, H., Nunes, A. L., et al. (2013a). Implementing the European policies for alien species networking, science, and partnership in a complex environment. Manag. Biol. Invasion 4, 3-6. doi:10.3391/mbi.2013.4.1.02

Katsanevakis, S., Gatto, F., Zenetos, A., and Cardoso, A. C. (2013b). How many marine aliens in Europe? Manag. Biol. Invasion 4, 37-42. doi:10.3391/ mbi.2013.4.1.05

Katsanevakis, S., Zenetos, A., Belchior, C., and Cardoso, A. C. (2013c). Invading European seas: assessing pathways of introduction of marine aliens. Ocean Coast. Manage. 76, 64-74. doi:10.1016/j.ocecoaman.2013.02.024

Katsanevakis, S., Tempera, F., and Teixeira, H. (2016). Mapping the impact of alien species on marine ecosystems: the Mediterranean Sea case study. Diversity Distrib. 22, 694-707. doi:10.1111/ddi.12429

Katsanevakis, S., Wallentinus, I., Zenetos, A., Leppäkoski, E., Çinar, M. E., Oztürk, B., et al. (2014). Impacts of marine invasive alien species on ecosystem services and biodiversity: a pan-European review. Aquat. Invasions 9, 391-423. doi:10.3391/ ai.2014.9.4.01

Kettunen, M., Genovesi, P., Gollasch, S., Pagad, S., and Starfinger, U. (2009). Technical Support to EU Strategy on Invasive Alien Species (IAS) - Assessment of the Impacts of IAS in Europe and the EU. Final Report for the European Commission. Brussels, Belgium: Institute for European Environmental Policy (IEEP), 44.

Lucy, F. E., Roy, H., Simpson, A., Carlton, J. T., Hanson, J. M., Magellan, K., et al. (2016). INVASIVESNET towards an International Association for open knowledge on invasive alien species. Manag. Biol. Invasion 7, 131-139. doi:10.3391/ mbi.2016.7.2.01 
McGeoch, M. A., Genovesi, P., Bellingham, P. J., Costello, M. J., McGrannachan, C., and Sheppard, A. (2015). Prioritizing species, pathways, and sites to achieve conservation targets for biological invasion. Biol. Invasions 18, 299-314. doi:10.1007/s10530-015-1013-1

McGeoch, M. A., Spear, D., Kleynhans, E. J., and Marais, E. (2012). Uncertainty in invasive alien species listing. Ecol. Appl. 22, 959-971. doi:10.1890/11-1252.1

Millennium Ecosystem Assessment (MEA). (2005). Ecosystems and Human Well-being: Biodiversity Synthesis. Washington, DC, USA: World Resources Institute.

Moustakas, A. (2017). Spatio-temporal data mining in ecological and veterinary epidemiology. Stoch. Environ. Res. Risk Assess 31, 829-834. doi:10.1007/ s00477-016-1374-8

Nunes, A. L., Katsanevakis, S., Zenetos, A., and Cardoso, A. C. (2014). Gateways to alien invasions in the European seas. Aquat. Invasions 9, 133-144. doi:10.3391/ ai.2014.9.2.02

Nunes, A. L., Tricarico, E., Panov, V. E., Cardoso, A. C., and Katsanevakis, S. (2015). Pathways and gateways of freshwater invasions in Europe. Aquat. Invasions 10, 359-370. doi:10.3391/ai.2015.10.4.01

Ojaveer, H., Galil, B. S., Minchin, D., Olenin, S., Amorim, A., Canning-Clode, J., et al. (2014). Ten recommendations for advancing the assessment and management of non-indigenous species in marine ecosystems. Mar. Policy 44, 160-165. doi:10.1016/j.marpol.2013.08.019

Panov, V., and Gollasch, S. (2004). "Informational resources on aquatic alien species in Europe on the internet: present developments and future perspectives," in UNESCO Proceedings of "The Colour of Ocean Data" Symposium, IOC Workshop Report 188. (France, Paris).

Panov, V. E., Gollasch, S., and Lucy, F. (2011). Open-access journal aquatic invasions: an important part of the developing European information and early warning system on invasive alien species. Aquat. Invasions 6, 1-5. doi:10.3391/ ai.2011.6.1.01

Perdikaris, C., Koustikos, N., Vardakas, L., Kommatas, D., Simonovic, P., Paschos, I., et al. (2016). Risk screening of non-native, translocated and traded aquarium freshwater fishes in Greece using Fish Invasiveness Screening Kit. Fisheries Manag. Ecol. 23, 32-43. doi:10.1111/fme.12149

Pergl, J., Pyšek, P., Bacher, S., Essl, F., Genovesi, P., Harrower, C. A., et al. (2017). Troubling travellers: are ecologically harmful alien species associated with particular introduction pathways? NeoBiota 32, 1-20. doi:10.3897/ neobiota.32.10199

Ricciardi, A., Hoopes, M. F., Marchetti, M. P., and Lockwood, J. L. (2013). Progress towards understanding the ecological impacts of nonnative species. Ecol. Monogr. 83, 263-282. doi:10.1890/13-0183.1

Roques, A. (2015). Drivers and pathways of forest insect invasions in Europe, can we predict the next arrivals? Accad. Naz. Ital. Entomol. Anno LXIII, 145-150.

Roques, A., Auger-Rozenberg, M. A., Blackburn, T. M., Garnas, J. R., Pyšek, P., Rabitsch, W., et al. (2016). Temporal and interspecific variation in rates of spread for insect species invading Europe during the last 200 years. Biol. Invasions 18, 907-920. doi:10.1007/s10530-016-1080-y

Roy, H. E., Adriaens, T., Aldridge, D. C., Bacher, S., Bishop, J. D. D., Blackburn, T. M., et al. (2015). Invasive Alien Species - Prioritising Prevention Efforts through Horizon Scanning. ENV.B.2/ETU/2014/0016. Brussels: European Commission.

Roy, H. E., Preston, C. D., Harrower, C. A., Rorke, S. L., Noble, D., Sewell, J., et al. (2014). GB non-native species information portal: documenting the arrival of nonnative species in Britain. Biol. Invasions 16, 2495-2505. doi:10.1007/ s10530-014-0687-0

Seebens, H., Blackburn, T. M., Dyer, E. E., Genovesi, P., Hulme, P. E., Jeschke, J. M., et al. (2017). No saturation in the accumulation of alien species worldwide. Nat. Commun. 8, 14435. doi:10.1038/ncomms 14435

Silver, N. (2012). The Signal and the Noise: Why So Many Predictions Fail-but Some Don't. London: Penguin Books.

Thiel, M., Penna-Díaz, M. P., Luna-Jorquera, G., Salas, S., Sellanes, J., and Stotz, W. (2014). Citizen scientists and marine research: volunteer participants, their contributions, and projection for the future. Oceanogr. Mar. Biol. Annu. Rev. 52, 257-314. doi:10.1201/b17143-6

Trombetti, M., Katsanevakis, S., Deriu, I., and Cardoso, A. C. (2013). EASIN-Lit: a geo-database of published alien species records. Manag. Biol. Invasion 4, 261-264. doi:10.3391/mbi.2013.4.3.08

Tsiamis, K., Cardoso, A. C., and Gervasini, E. (2017a). The European alien species information network on the convention on biological diversity pathways categorization. NEOBIOTA 32, 21-29. doi:10.3897/neobiota.32.9429

Tsiamis, K., Gervasini, E., Deriu, I., D’Amico, F., Nunes, A., Addamo, A., et al. (2017b). Baseline Distribution of Invasive Alien Species of Union Concern. Ispra, Italy: Publications Office of the European Union. EUR 28596 EN.

Tsiamis, K., Gervasini, E., D’Amico, F., Deriu, I., Roglia, E., Shade, S., et al. (2017c). Citizen Science Application, Invasive Alien Species in Europe. Ispra, Italy: Publications Office of the European Union. EUR $28441 \mathrm{EN}$.

Tsiamis, K., Gervasini, E., D’Amico, F., Deriu, I., Katsanevakis, S., Crocetta, F., et al. (2016). The EASIN Editorial Board: quality assurance, exchange and sharing of alien species information in Europe. Manag. Biol. Invasion 7, 312-328. doi:10.3391/mbi.2016.7.4.02

Williamson, M., and Fitter, A. (1996). The varying success of invaders. Ecology 77, 1661-1666. doi:10.2307/2265769

Conflict of Interest Statement: The authors declare that the research was conducted in the absence of any commercial or financial relationships that could be construed as a potential conflict of interest.

Copyright (c) 2017 Deriu, D'Amico, Tsiamis, Gervasini and Cardoso. This is an open-access article distributed under the terms of the Creative Commons Attribution License (CC BY). The use, distribution or reproduction in other forums is permitted, provided the original author(s) or licensor are credited and that the original publication in this journal is cited, in accordance with accepted academic practice. No use, distribution or reproduction is permitted which does not comply with these terms. 